\title{
Information technologies in local geophysical process management methodology
}

\author{
Oleksandr Maevsky ${ }^{1}$, Volodymyr Artemchuk ${ }^{2,3,{ }^{*}, \text { Yuri Brodsky }}{ }^{1}$, Pavlo Topolnytskyi ${ }^{1}$, and Chijioke Ikokwu $^{4}$ \\ ${ }^{1}$ Polissia National University, 7 Stary Boulevard, Zhytomyr, 10002, Ukraine \\ ${ }^{2}$ G.E. Pukhov Institute for Modelling in Energy Engineering of NAS of Ukraine, 15 General Naumov Str., Kyiv, 03164, Ukraine \\ ${ }^{3}$ State Institution "The Institute of Environmental Geochemistry of National Academy of Sciences of Ukraine”, 34a Palladin Ave., \\ Kyiv, 03142, Ukraine \\ ${ }^{4}$ International Tourism and Sustainability Centre, Garki 2, Abuja, 900242, Nigeria
}

\begin{abstract}
The authors propose an approach to assessing the possibility of stabilizing controlled impact on the ecological system, its climatic characteristics, within a limited space. Maintaining the necessary climatic parameters at an acceptable level ensures the stability of any ecosystem, the natural habitat of all living organisms, the preservation of biodiversity, including humans. The biggest potential threat is the rapid dynamics of global warming. Rising temperatures are the cause of extreme weather events, which directly affects environmental and food security. Given the urgency of the task, there is a need to study the controlled mechanism of influence on certain climatic factors in order to curb abnormal dynamics and bring the ecosystem into a state of stable equilibrium. The approach proposed by the authors is based on modeling the process of reducing the risk of crisis situations with abnormal fluctuations in ambient temperature. The mathematical model is represented by a system of ordinary differential equations, which is a consequence of the adaptation of Lagrange equations to oscillatory processes. The state of the studied climatic factor is matched by some random process, the amplitude of which depends on the values of the components of the control vectors and the function of external influence. The experimental parameter is ambient temperature. The problem was solved using statistical data for the Zhytomyr region (Ukraine). The main results of the simulation are to obtain a set of control vectors and functions of external influence, which will be taken into account in the information system for monitoring the environmental situation.
\end{abstract}

\section{Introduction}

The development of various spheres of human activity, especially technology, especially information, clearly contributes to the positive growth of the level of civilization in general, but at the same time carries a negative component, which at first seems invisible, and then often simply ignored. This component is the current environmental problems, the exacerbation of which is associated with the processes of negative anthropogenic impact. For example, the impact on natural processes of climate change in many regions of the globe, the trend of global warming, which, uncontrollably developing, lead to terrible catastrophic consequences.

This article is a continuation of previous research by the authors [1-4] and their colleagues [5-16] in the field of improving the efficiency of management decisions, environmental safety issues, development of appropriate software, etc.

The main purpose of previous author's study [2] is the presentation of the conceptual approach to the development of software tools for the analysis and synthesis of a geophysical monitoring systems model. To achieve this goal, two approaches are proposed to describe the interaction "humanity - the environment". The first approach is based on the use of "game principles". The "game principle" of humanity and the environment can be described using a system of ordinary differential equations, pre-determined with the phase coordinates and "controls" of the players, as "control" affects the phase coordinates. At the heart of the second approach, the environment is considered as a system characterized by fluctuations under the influence of anthropogenic load. Depending on the level of external influence, the system either returns to equilibrium or as a result of increasing the amplitude of oscillations is destroyed and not restored, which is equivalent to a catastrophic state. The paper [2] substantiates the model of the geophysical monitoring system based on the Lagrange equations for an oscillatory system with two or more degrees of freedom in the "factor space", and the model based on "game principles". Also shown the block diagram algorithm of the analysis and synthesis of geophysical monitoring systems models.

Some environmental, information, and other aspects of geophysical monitoring systems models are presented in papers [17-38].

For example, the author of [22] writes, that the

\footnotetext{
* Corresponding author: ak24avo@gmail.com
} 
technosphere metabolizes not only energy and materials but information and knowledge as well. The article first examines the history of knowledge about large-scale, long-term, anthropogenic environmental change. Also, the author proposes that knowledge infrastructures for the Anthropocene might not only monitor and model the technosphere's metabolism of energy, materials, and information but also integrate those techniques with new accounting practices aimed at sustainability.

The paper [26] presents a variational approach to solving direct and inverse problems based on the joint use of mathematical models and data monitoring of processes of geophysical hydro-thermodynamics. This approach is used to solve problems related to environmental protection.

A good illustration of interconnected geophysical processes in the environment on the example of the Arctic region is shown in paper [30].

A lot of game models for particular issues of humanenvironment systems are shown in papers [31-38] and others. For example, authors [33] to illustrate the applicability of their results analyze stochastic models of evolutionary games, Lotka-Volterra dynamics, trait evolution, and spatially structured disease dynamics. Analysis of these models demonstrates environmental stochasticity facilitates the coexistence of strategies in the hawk-dove game, but inhibits coexistence in the rockpaper-scissors game and a Lotka-Volterra predator-prey model.

The extreme urgency of environmental (climatic) problems gives a significant impetus to the study of such processes in ecological systems. Therefore, in order to study the mechanism of climate control, there is an urgent need to develop mathematical and simulation models using information technology (including artificial intelligence systems) in the interests of the safe development of society. The complexity of creating a perfect information system for managing global climate parameters leads to a narrowing of the task to the local level of a particular region.

The aim of the article is to develop a conceptual approach to modeling natural processes in the problem of studying the mechanism of climate control.

\section{Methods}

To solve this problem, we present the environment in the form of a system, which is characterized by fluctuations under the influence of anthropogenic load. In this case, depending on the level of external influence, the system either returns to equilibrium or, as a result of increasing the amplitude of oscillations, is destroyed and not restored, which is equivalent to a catastrophic state [1]. Since the result of general warming is an increase in the average temperature of the planet's atmosphere, it is advisable to choose the climatic parameter is the temperature. Accordingly, the mathematical model should describe the process of temperature control within the specified limits for a certain time of year in the selected local space.
The construction of the mathematical model assumes the availability of the necessary information about the factors influencing the temperature of the atmosphere, as well as the nature of the seasonal temperature dynamics of the selected research region: Zhytomyr (Ukraine), winter, December 2019. It is taken into account that solar activity, in general, is a slowly changing function of time [17], as well as the temperature component due to the distribution of radioactive substances in the earth's crust, the cloud layer is generally stable over time, natural emissions (e.g. volcanic activity) of pollutants in the atmosphere is absent, the movement of air masses is moderate.

Analysis of statistical data allows us to outline the main assumptions of the model: 1) seasonal dynamics of the region's atmospheric temperature is fluctuating; 2) temperature oscillating process is random; 3) surface air temperature is a function of such factors as solar activity, distribution of radioactive substances in the earth's crust, air mass movement, the stability of the cloud layer, emissions of pollutants of natural and anthropogenic origin, etc.

In the first approximation, it is expedient to consider the surface temperature of the region as a function of the concentration of emissions of harmful substances of anthropogenic origin and time at fixed values of other parameters of influence and external function of the thermal influence of anthropogenic origin. Thus, the task is to study the dynamics of the component of the temperature regime of the surface layer of the atmosphere of the selected region, which is due to the level of emission concentrations of pollutants of anthropogenic origin (mobile and stationary emission sources) and their thermal effects.

\section{Results and discussion}

\subsection{Formulation of the problem}

Consider the temperature $\theta$ as a function of two parameters: $\theta\left(t, c_{S}\right)$, where $c_{S}$ is the average monthly concentration $\left(\mathrm{mg} / \mathrm{m}^{3}\right)$ of emissions of harmful substances into the atmosphere of anthropogenic origin, $t$ is the time (from the first to the last day of the selected month). At a fixed value of $c_{S}$, we obtain the dependence of $\theta(t)$, Fig. 1.

Since the studied oscillatory process is random, it is expedient to describe it using a set of systems of secondorder differential equations, which are a consequence of the adaptation of Lagrange equations to oscillatory systems [2]. In this case, one phase variable $c_{S}$ is fixed, and the second phase variable $\theta(t)$ is controlled.

Then, within the framework of this goal, it is necessary to obtain a set of control vectors of the form $\vec{\varphi}=\left[\begin{array}{c}a_{0} \\ a_{1} \\ . \\ a_{n}\end{array}\right]$, as well as the function of the external thermal influence $W(t)$ for each implementation of the random process $\theta(t)$. 


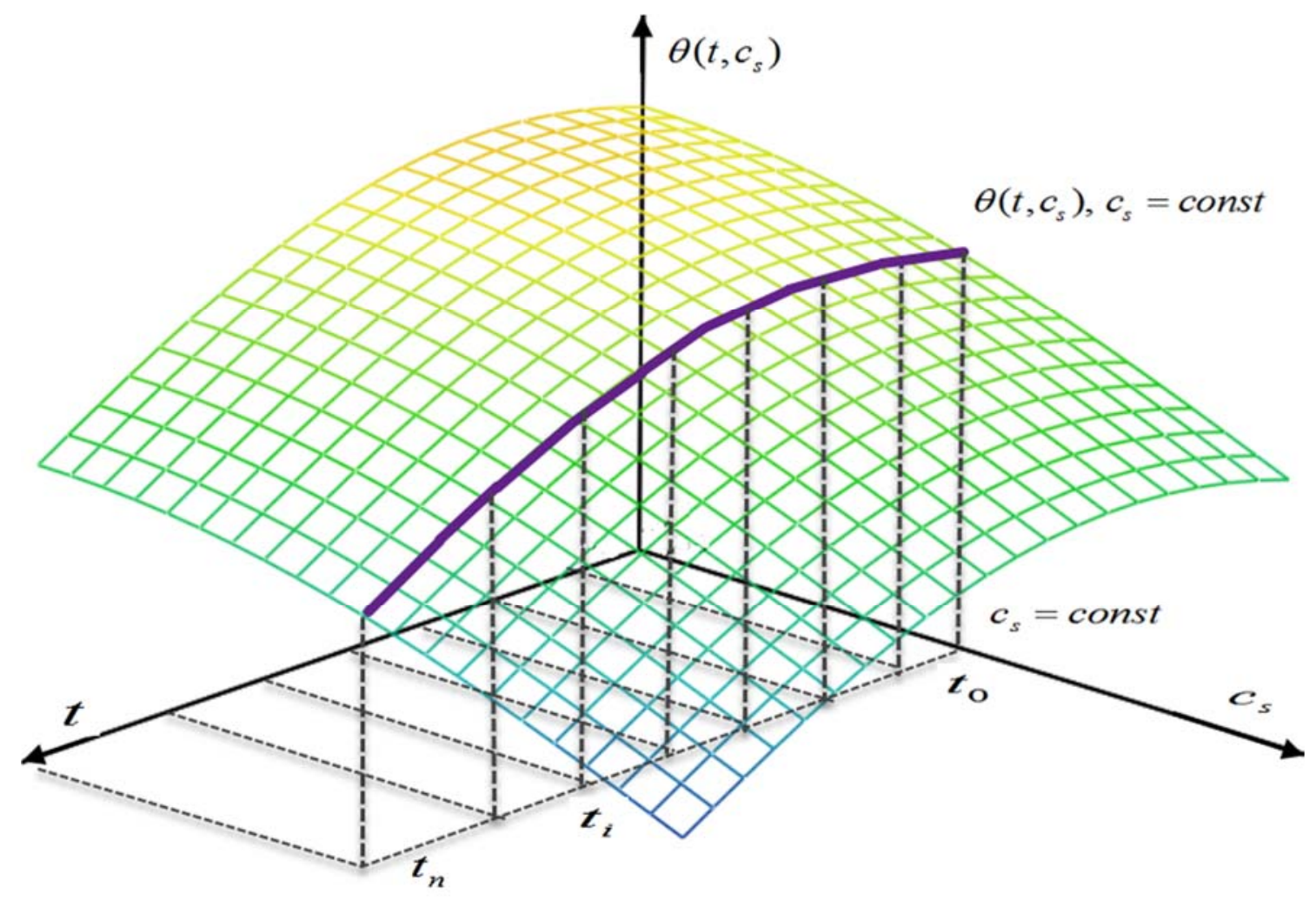

Fig. 1. Function $\boldsymbol{\theta}\left(\boldsymbol{t}, \boldsymbol{c}_{\boldsymbol{S}}\right)$ at a fixed value of $\boldsymbol{c}_{\boldsymbol{S}}$.

The values of the components of the set of control vectors $\vec{\varphi}$ must unambiguously ensure that the phase variable $\theta(t)$ is within certain limits, then the dynamics of the variable $\theta(t)$ is controlled. In contrast to mathematical models that extrapolate the dynamics of the studied process by a polynomial of degree $n$, the proposed model not only allows you to control the dynamics of the local process, but also to establish the type of function of thermal external influence.

\subsection{The algorithm}

The algorithm for controlling the temperature in a given space (region) is reduced to the following procedural steps: 1) generation of a set of control vectors $\vec{\varphi}$ and determination of the function of external thermal influence $W(t)$, at which the dynamics of temperature $\theta(t)$ does not exceed the specified limits (the authors solved this problem using the developed software in MathCAD [39] and Python [40]); 2) based on the obtained simulation results, a decision is made (for example, by an artificial intelligence system) to regulate the concentration of pollutant emissions into the atmosphere for a given region; 3) after the introduced corrections, the cycle of generation of control vectors and determination of the function of external thermal influence $W(t)$ is repeated until the dynamics of the variable $\theta(t)$ is stable within the selected limits.

The resulting system of differential equations is solved by the numerical Runge-Kutta method with a fixed step. The components of the control vector $\vec{\varphi}$ have a uniform distribution law.

\subsection{The computational experiment and discussion}

Zhytomyr (Ukraine) and the Zhytomyr region (see Fig.2) were chosen for the computational experiment.

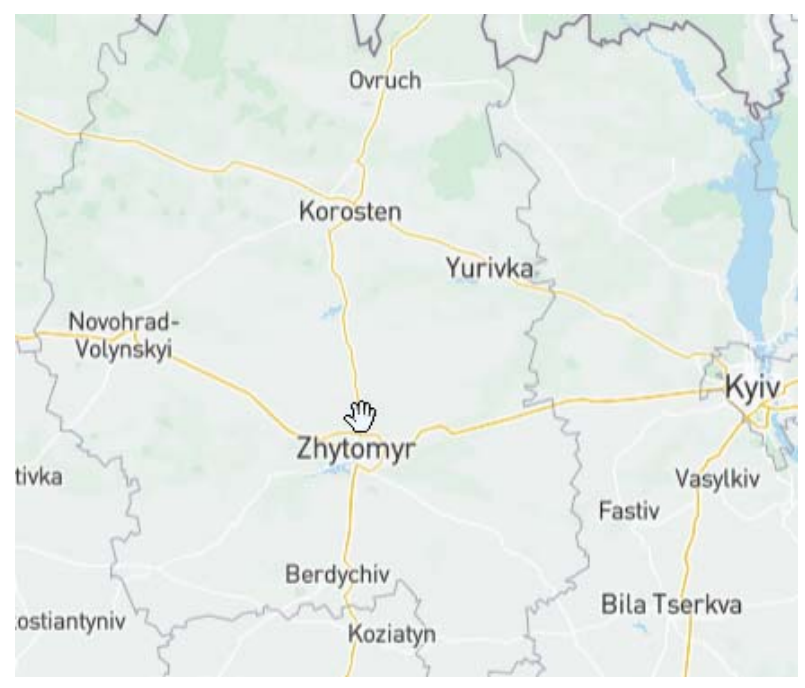

Fig. 2. Location of the research area: Zhytomyr (Ukraine), and Zhytomyr region.

Table 1 presents the statistical values of atmospheric air temperature provided by the meteorological complex (WMO Index 33325. Latitude: $50.270^{\circ}$; longitude: $28.630^{\circ}$ ) for December 2019.

After adapting the Lagrange equations [2] to the oscillatory system, we obtain the usual linear, 
inhomogeneous differential equation of the second order:

$$
\frac{d^{2} \theta(t)}{d t^{2}}+A_{0} \frac{d \theta(t)}{d t}+A_{1} \theta(t)+A_{2} c_{S}=A_{3} W(t),
$$

where $A_{0}, A_{1}, A_{2}, A_{3}$ - coefficients to be determined;

$W(t)$ - the function of external thermal influence, which is to be determined;

$c_{S}$ is the average concentration of pollutants in the surface layer of the atmosphere in the study area for a fixed period.

Table 1. Atmospheric air average temperature values for December $2019, \mathrm{t}^{\circ} \mathrm{C}$.

\begin{tabular}{|c|c|c|}
\hline 1 decade & 2 decade & 3 decade \\
\hline 0.2 & 2.1 & 6.6 \\
\hline-1.3 & 2.2 & 5.6 \\
\hline-0.5 & 0.1 & 6.7 \\
\hline-0.4 & 0.5 & 7.8 \\
\hline 1.9 & 4.2 & 5.5 \\
\hline 0.8 & 7.2 & 3.7 \\
\hline 0.7 & 6.5 & 1.1 \\
\hline 4.2 & 8.4 & 0.1 \\
\hline 3.6 & 6.7 & -0.9 \\
\hline 0.6 & 2.9 & -3.6 \\
\hline$* *$ & $* *$ & 2.0 \\
\hline
\end{tabular}

Note that the components of the control vectors are different for each implementation of the dynamics of $\theta(t)$.

The dimension of the components of the control vectors and the functions of the external thermal influence, respectively:

$\mathrm{A}_{0}=\left[\mathrm{s}^{-1}\right] ; \mathrm{A}_{1}=\left[\mathrm{s}^{-2}\right] ; \mathrm{A}_{2}=\left[\mathrm{s}^{-2} \mathrm{mg}^{-1} \mathrm{~m}^{3}\right] ; \mathrm{A}_{3}=\left[\mathrm{s}^{-2}\right] ;$

$\mathrm{W}(\mathrm{t})=\left[{ }^{\circ} \mathrm{C}\right]$.

The dimensionality of these coefficients can also be expressed in terms of units, namely [m] and [s]. That is, because of the spatial and temporal dimensions.

After the introduction of auxiliary functions, equation (1) will become a system of ordinary differential equations of the form:

$$
\left\{\begin{array}{l}
\frac{d y_{2}}{d t}=-A_{0} y_{2}-A_{1} y_{1}-A_{2} c_{s}+A_{3} W(t) \\
\frac{d y_{1}}{d t}=y_{2}
\end{array},\right.
$$

where $\theta(t)=y_{1}, \theta^{\prime}(t)=y_{2}$ is the function of temperature change over time and the function of the rate of temperature change over time, respectively.

Fig. 3 presents the dynamics of statistical temperature values for December 2019, in accordance with the data in table 1.

For further processing of statistical data, we perform interpolation of statistical data by a power polynomial of the third-order by means of MathCAD.

The result of interpolation and the dynamics of statistical temperature data are presented in Fig. 4; time $t$ - days of the month with a step of 0.31 days (total 101 steps).

The fragment of the matrix $Y_{S}(t)^{T}$ with the results of interpolation, is presented in Fig. 5

The next stage of modeling involves determining the composition of surface temperature that depends on the average monthly concentration of emissions of harmful substances into the atmosphere and the function of external thermal influence.

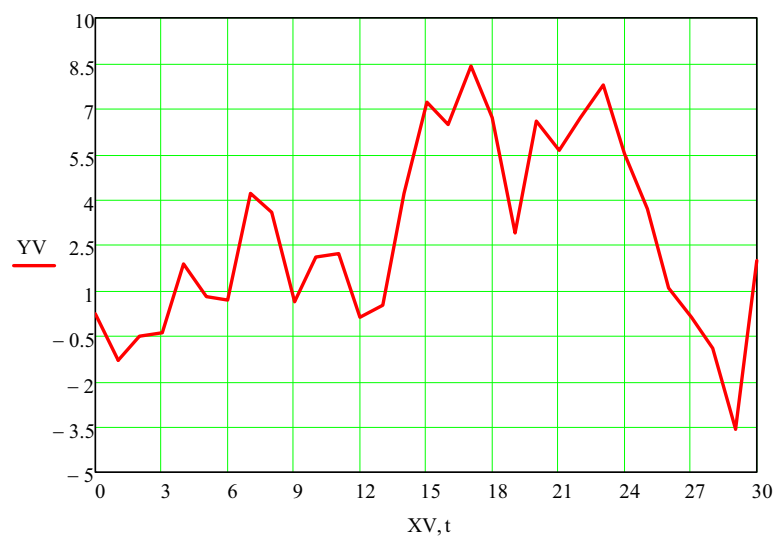

Fig. 3. Dynamics of $Y V$ statistical temperature values for December 2019, according to Table 1.

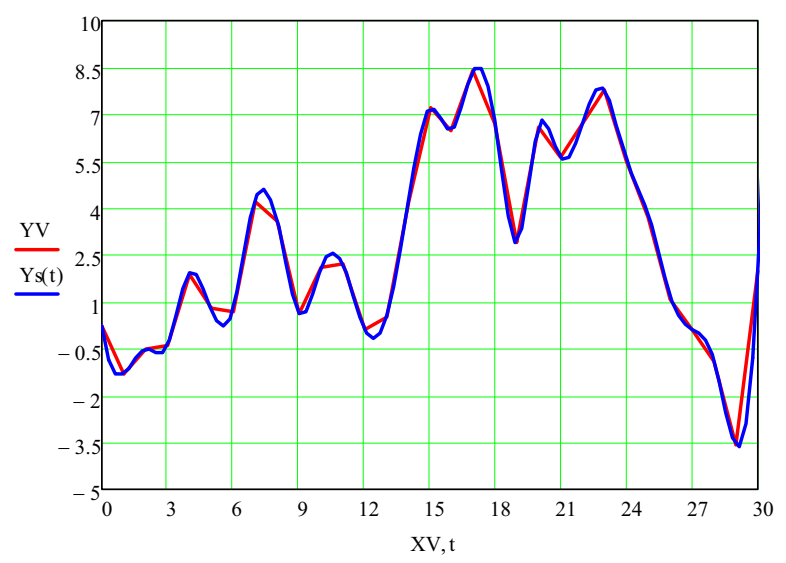

Fig. 4. The result of interpolation $Y_{S}(t)$ and the dynamics of $Y V$

\begin{tabular}{|c|c|c|c|c|c|}
\hline${ }^{T}(t)$ & 0 & 1 & 2 & 3 & 4 \\
\hline 0 & 0.2 & -0.835 & -1.292 & -1.332 & -1.115 \\
\hline
\end{tabular}
statistical temperature values for December 2019.

Fig. 5. The fragment of the matrix $Y_{S}(t)^{T}$ with the results of interpolation.

Preliminarily, we establish the form of the slowly changing time function $P(t)$, which reflects the dynamics of the temperature component as a result of the combined influence of other factors (the main factor is seasonal solar activity).

The results obtained using the MathCAD system, allow us to represent the function $P(t)$ as follows:

$P(t)=0,1737-0,2792 \mathrm{t}+0,0679 \mathrm{t}^{2}-0,002 \mathrm{t}^{3}$

The graph of the slowly changing time function $P(t)$ is presented in Fig. 6.

Some of the values of this function are represented by a fragment of the TREND ${ }^{\mathrm{T}}$ matrix in Fig. 7.

Then the rapidly oscillating component of the BOOSK temperature, which is due to the anthropogenic factor of influence will have the form shown in Fig. 8.

Accordingly, the values of the rapidly oscillating component of the BOOSK temperature, which is due to the anthropogenic factor of influence, are represented by a fragment of the BOOSK matrix in Fig.9.

From the graph in Fig. 8, the upper and lower limits of the range of oscillations of the fast-oscillating temperature component BOOSK, which is due to anthropogenic 
factor, and requires the determination of many control vectors $\vec{\varphi}$, providing a set control range for each implementation of the oscillatory process described by equation (1).

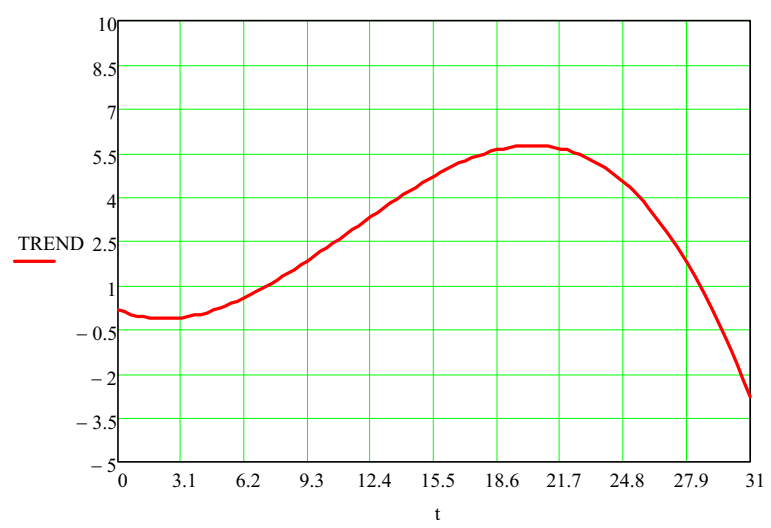

Fig. 6. The graph of the slowly changing time function $P(t)$.

\begin{tabular}{|c|c|c|c|c|c|c|}
\hline \multirow{2}{*}{ TREND $^{T}=$} & & 0 & 1 & 2 & 3 & 4 \\
\hline & 0 & 0.174 & 0.094 & 0.026 & -0.029 & -0.072 \\
\hline
\end{tabular}

Fig. 7. The fragment of the TREND ${ }^{\mathrm{T}}$ matrix.

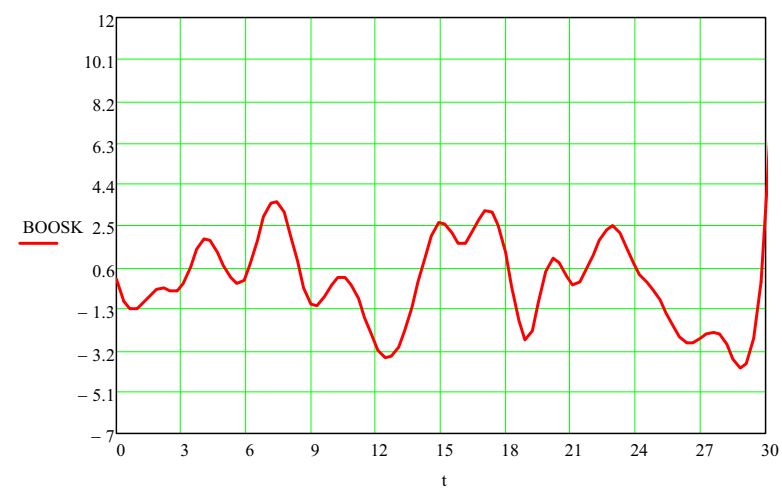

Fig. 8. The rapidly oscillating component of the BOOSK temperature, which is due to the anthropogenic factor of influence.

The final stage of modeling involves multiple implementations of the computational algorithm in MathCAD or Python. The experiment performed 901 iterations of the computational algorithm and obtained, respectively, 901 control vector $\vec{\varphi}$, which provides the dynamics of $\theta(t)$, i.e. the rapidly oscillating temperature component, which is due to an anthropogenic factor in a given range of fluctuations for a given month.

For example, three of the 901 calculated control vectors are shown in Table 2 (numbering begins with zero iteration).

Table 2. The values of the components of the control vectors $\vec{\varphi}$ for iterations № 0, № 110, № 700 .

\begin{tabular}{|c|c|c|c|}
\hline $\begin{array}{c}\text { Control vector } \\
\vec{\varphi} \text { component }\end{array}$ & $\begin{array}{c}\text { Iteration } \\
\text { № 0 }\end{array}$ & $\begin{array}{c}\text { Iteration } \\
\text { № 110 }\end{array}$ & $\begin{array}{c}\text { Iteration } \\
\text { № 700 }\end{array}$ \\
\hline$a_{0}$ & $1.624 \times 10^{-6}$ & $1.298 \times 10^{-6}$ & $3.731 \times 10^{-7}$ \\
\hline$a_{1}$ & $2.986 \times 10^{-6}$ & $1.180 \times 10^{-6}$ & $4.574 \times 10^{-6}$ \\
\hline$a_{2}$ & $3.591 \times 10^{-6}$ & $1.343 \times 10^{-6}$ & $3.777 \times 10^{-6}$ \\
\hline$a_{3}$ & $2.967 \times 10^{-6}$ & $3.997 \times 10^{-6}$ & $5.086 \times 10^{-7}$ \\
\hline
\end{tabular}

\begin{tabular}{|c|r|}
\hline & \multicolumn{1}{|l|}{0} \\
\hline 0 & 0.026 \\
\hline 1 & -0.928 \\
\hline 2 & -1.318 \\
\hline 3 & -1.303 \\
\hline 4 & -1.043 \\
\hline 5 & -0.698 \\
\hline 6 & -0.426 \\
\hline 7 & -0.377 \\
\hline 8 & -0.483 \\
\hline 9 & -0.485 \\
\hline 10 & -0.122 \\
\hline 11 & 0.634 \\
\hline 12 & 1.436 \\
\hline 13 & 1.905 \\
\hline 14 & 1.801 \\
\hline 15 & $\ldots$ \\
\hline
\end{tabular}

Fig. 9. The value of the rapidly oscillating component of the BOOSK temperature, which is due to the anthropogenic factor.

As noted above, the components of the set of control vectors $\vec{\varphi}$, ie $a_{0}, a_{1}, a_{2}, a_{3}$, are distributed according to the uniform law.

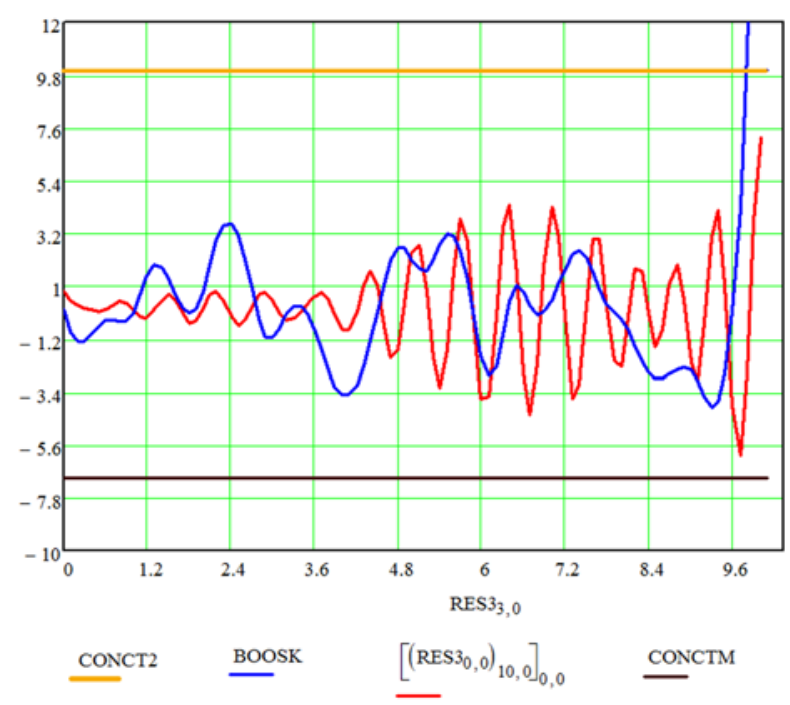

Fig. 10. The value of the rapidly oscillating component of the BOOSK temperature, which is due to the anthropogenic factor of influence. CONCT2 - the upper limit of the range of temperature fluctuations, is $+10^{\circ} \mathrm{C}$. CONCTM - the lower limit of the range of temperature fluctuations is $-7^{\circ} \mathrm{C}$. RES $3_{10.0}$ is a simulated implementation (as an example of iteration №10) of the dynamics of a function whose oscillation limits correspond to the set range. $R E S 3_{3.0}$ - days of the month with a step of 0.31 days.

In this case, according to the simulation results, the coefficients $A_{0}, A_{1}, A_{2}, A_{3}$ of the differential equation (1) will have the form: $A_{0}=a_{0}+0,0005 ; A_{1}=a_{1}+$ 20,8; $A_{2}=a_{2}+0,4 ; A_{3}=a_{3}+5,4$, and the function $W(t)$ of external thermal influence for the controlled process of dynamics of $\theta(t)$ will have the form: 


$$
W(t)=(0,49 t)^{2,1} \operatorname{Sin}(10,2 t)+1,5 t \operatorname{Cos}(9 t-7)+30
$$

The estimated average concentration $c_{S}$ of pollutants in the surface layer of the atmosphere of the selected region is $400 \mathrm{mg} / \mathrm{m}^{3}$.

Fig. 10 shows the dynamics of the rapidly oscillating temperature component, which is due to the anthropogenic factor of influence and is limited by the corresponding range of oscillations and simulates the results of the controlled process in the same range that was set.

The analysis of Fig. 10 shows that the set of solutions of equation (1) in general reproduces the dynamics of the rapidly oscillating temperature component, which is due to the anthropogenic factor of influence by emissions of pollutants into the surface layer of atmospheric air of the studied region.

For most of the period (31 days), the phase development of the simulated process is synchronous with the statistical. Partial amplitude discrepancies are observed.

In this case, a significant part of the statistical fluctuations is absorbed by the simulated process.

\section{Conclusions}

Based on the simulation results, it is proved that the set of solutions of equation (1) in general reproduces the dynamics of the rapidly oscillating temperature component, which is due to the anthropogenic factor by emissions of pollutants into the surface layer of atmospheric air of the studied region. The complexity of creating a perfect information system for managing global climate parameters leads to a narrowing of the task to the local level of a particular region.

For most of the period (31 days), the phase development of the simulated process is synchronous with the statistical. Partial amplitude discrepancies are observed.

In this case, a significant part of the statistical temperature fluctuations is absorbed by the simulated oscillatory process of the temperature regime.

Since the most important factor is to maintain a controlled temperature within the specified limits, the proposed mathematical model is adequate.

Unlike mathematical models that extrapolate the process, the proposed mathematical control model allows not only to determine the set of process control vectors but also to establish the form of the function of external thermal influence.

At small values of the component of the control vectors $\vec{\varphi}$, the process is easily controlled and there is a 901 process control vector within the specified limits. Therefore the criterion for the proven reliability of the obtained models is the power of the set of control vectors.

As the simulation results show, there are certain limits to the values of the control vector components and, as a consequence, the set of control vectors themselves can be significantly reduced when approaching the limit values of the control vector components.

That is, for example, from 901 computational iterations, only one control vector $\vec{\varphi}$ can correspond at fixed input parameters.

Since the simulation results are obtained solely through the use of information technology, the number of iterations of the computational algorithm is limited by hardware resources.

Thus, with the increase of computational steps in the Runge-Kutta method to 1000 and setting the number of iterations to more than 3000 , there is a conflict between the computational algorithm and the hardware on which the computational experiment was conducted.

Further development of the proposed approach involves the use of artificial intelligence systems and the application to other similar geophysical phenomena of regional nature.

\section{References}

1. O. Maevsky, V. Artemchuk, Y. Brodsky, I. Pilkevych, P. Topolnitsky, Modeling of the Process of Optimization of Decision-Making at Control of Parameters of Energy and Technical Systems on the Example of Remote Earth's Sensing Tools, in Studies in Systems, Decision and Control, vol. 298, ed. by V. Babak, V. Isaienko, A. Zaporozhets (Springer, Cham, 2020), pp. 111-122. doi:10.1007/978-3-03048583-2 7

2. O. Maevsky, V. Artemchuk, Y. Brodsky, L. Makarenko, Y. Shpylovyi, The Conceptual Approach to the Development of Software Tools for Analysis and Synthesis of Geophysical Monitoring Systems Models, in Studies in Systems, Decision and Control (Springer, Cham, 2021 to be published)

3. A. Iatsyshyn, A. Iatsyshyn, V. Artemchuk, I. Kameneva, V. Kovach, O. Popov, Software tools for tasks of sustainable development of environmental problems: peculiarities of programming and implementation in the specialists' preparation. E3S Web Conf. 166, 01001 (2020). doi:10.1051/e3sconf/202016601001

4. A. Iatsyshyn, A. Iatsyshyn, V. Kovach, I. Zinovieva, V. Artemchuk, O. Popov, O. Cholyshkina, O. Radchenko, O. Radchenko, A. Turevych, Application of Open and Specialized Geoinformation Systems for Computer Modelling Studying by Students and PhD Students. CEUR Workshop Proceedings 2732, 893-908 (2020), http://ceurws.org/Vol-2732/20200893.pdf. Accessed 25 Nov 2020

5. S. Semerikov, S. Chukharev, S. Sakhno, A. Striuk, V. Osadchyi, V. Solovieva, T. Vakaliuk, P. Nechypurenko, O. Bondarenko, H. Danylchuk, Our sustainable coronavirus future. E3S Web Conf. 166, 00001 (2020).

6. R. Mergner et al., Fostering sustainable feedstock production for advanced biofuels on underutilised land in Europe. In European Biomass Conference and Exhibition Proceedings 2017, 125-130 (2017)

7. V. Kovach, G. Lysychenko, Toxic Soil Contamination and Its Mitigation in Ukraine, in Soil 
Science Working for a Living, ed. by D. Dent, Y. Dmytruk (Springer, Cham, 2017). doi:10.1007/9783-319-45417-7 18

8. O. Popov, A. Yatsyshyn, Mathematical Tools to Assess Soil Contamination by Deposition of Technogenic Emissions, in Soil Science Working for a Living, ed. by D. Dent, Y. Dmytruk (Springer, Cham, 2017). doi:10.1007/978-3-319-45417-7_11

9. T. Yatsyshyn, L. Shkitsa, O. Popov, M. Liakh, Development of mathematical models of gas leakage and its propagation in atmospheric air at an emergency gas well gushing. Eastern-European Journal of Enterprise Technologies 5/10(101), 49-59 (2019). doi:10.15587/1729-4061.2019.179097

10. L. Shkitsa, T. Yatsyshyn, M. Lyakh, O. Sydorenko, Innovative approaches to the formation of environmental safety at the objects of oil and gas production. IOP Conf. Ser.: Mater. Sci. Eng. 749, 012009 (2020). doi:10.1088/1757899X/749/1/012009

11. I. Melnychuk, O. Savko, S. Pobihun, N. Havadzyn, The impact of a country's level of economic development on environmental safety. Procedia Environmental Science, Engineering and Management (2020 to be published)

12. M.L. Myrontsov, Multi-Probe Hardware for Electrometry of Oil and Gas Wells, Science and innovation $\quad \mathbf{1 4}(3), \quad 51-56 \quad$ (2018). doi: $15407 /$ scine 14.03 .051

13. A.O. Zaporozhets, V.V. Khaidurov, Mathematical Models of Inverse Problems for Finding the Main Characteristics of Air Pollution Sources. Water, Air, Soil Pollut. 231, 563 (2020). doi:10.1007/s11270020-04933-z

14. A. Zaporozhets, V. Babak, V. Isaienko, K. Babikova, Analysis of the Air Pollution Monitoring System in Ukraine, in Studies in Systems, Decision and Control, vol. 298, ed. by V. Babak, V. Isaienko, A. Zaporozhets (Springer, Cham, 2020), pp. 85-110. doi:10.1007/978-3-030-48583-2_6

15. N. Pobihun, Y. Korobeinykova, O. Pobihun, I. Iuras, Ecological and monitoring studies of oil production territories and possibility of their use in recreation, in Proceedings of the XIII International Scientific Conference "Monitoring of Geological Processes and Ecological Condition of the Environment", vol. 2019, pp. 1-5. (2019). doi:10.3997/22144609.201903183

16. Y. Balashevska, Y. Kyrylenko, O. Pecherytsia, I. Shevchenko, V. Bogorad, Harmonization of Methodological Approaches and Real Time Radiological Consequence Forecasting Tools. Nucl. Radiat. Saf. 2(86), 20-26 (2020). doi:10.32918/nrs.2020.2(86).03

17. K.A. Karimov, R.D. Gainutdinova, Role of different physical factors in long-term changes of surface temperature. Proceedings of Hydrometcentre of Russia 366, 121-136 (2017)
18. J.K. Alvarez, S. Sutjipto, S. Kodagoda, Validated ground penetrating radar simulation model for estimating rebar location in infrastructure monitoring. Proceedings of the 2017 12th IEEE Conference on Industrial Electronics and Applications (2018). doi:10.1109/ICIEA.2017.8283069

19. M. Azpiroz-Zabala, M.J.B. Cartigny, E.J. Sumner, M.A. Clare et al., A general model for the helical structure of geophysical flows in channel bends. Geophysical Research Letters 44(23), 1193211941. (2017). doi:10.1002/2017GL075721

20. F. Dammeier, J.R. Moore, C. Hammer, F. Haslinger, $\mathrm{S}$ Loew, Automatic detection of alpine rockslides in continuous seismic data using hidden Markov models. Journal of Geophysical Research: Earth Surface 121(2), 351-371 (2016). doi:10.1002/2015JF003647

21. V. Di Fiore, M. Punzo, D. Tarallo, D., G. Cavuoto, Application of innovative geophysical techniques in coastal areas. Geophysics: Principles, applications and emerging technologies, pp. 47-59 (2016).

22. P.N. Edwards, Knowledge infrastructures for the anthropocene. Anthropocene Review 4(1), 34-43. (2017). doi:10.1177/2053019616679854

23. F. Greco et al., A multidisciplinary strategy for in-situ and remote sensing monitoring of areas affected by pressurized fluids: Application to mud volcanoes: A multidisciplinary environmental monitoring strategy. SAS 2016 - Sensors Applications Symposium, Proceedings 291-296.

(2016). doi:10.1109/SAS.2016.7479861

24. S. Li, R. Hu, Numerical simulation of ground penetrating radar based on advanced prediction of adverse geological bodies. IOP Conference Series: Earth and Environmental Science 371(2) (2019). doi:10.1088/1755-1315/371/2/022038

25. S. Marullo, P.J. Minnett, R. Santoleri, M. Tonani, The diurnal cycle of sea-surface temperature and estimation of the heat budget of the Mediterranean sea. Journal of Geophysical Research: Oceans 121(11), 8351-8367 (2016). doi:10.1002/2016JC012192

26. V.V. Penenko, A. V., Penenko, E.A. Tsvetova, Variational approach to the study of processes of geophysical hydro-thermodynamics with assimilation of observation data. Journal of Applied Mechanics and Technical Physics 58(5), 771-778 (2017). doi:10.1134/S0021894417050029

27. P. Schattan et al., Continuous monitoring of snowpack dynamics in alpine terrain by aboveground neutron sensing. Water Resources Research 53(5), 3615-3634 (2017). doi:10.1002/2016WR020234

28. J.S. Schlosser et al., Analysis of aerosol composition data for western united states wildfires between 2005 and 2015: Dust emissions, chloride depletion, and most enhanced aerosol constituents. Journal of Geophysical Research: Atmospheres 122(16), 89518966 (2017). doi:10.1002/2017JD026547 
29. J.R. Schroeder et al., Formaldehyde column density measurements as a suitable pathway to estimate nearsurface ozone tendencies from space. Journal of Geophysical Research 121(21), 13,088-13,112 (2016). doi:10.1002/2016JD025419

30. F.J. Wrona et al., Transitions in Arctic ecosystems: Ecological implications of a changing hydrological regime. Journal of Geophysical Research G: Biogeosciences 121(3), 650-674 (2016). doi:10.1002/2015JG003133

31. X. Bao, H. Li, Study on the evaluation method of subgrade slope green protection effect in dry-hot valley of sichuan-tibet railway. Mathematical Problems in Engineering (2020). doi:10.1155/2020/7159582

32. C.T. Bauch, R. Sigdel, J. Pharaon, M. Anand, Early warning signals of regime shifts in coupled humanenvironment systems. Proceedings of the National Academy of Sciences of the United States of America 113(51), 14560-14567 (2016). doi:10.1073/pnas.1604978113

33. M. Benaim, S.J. Schreiber, Persistence and extinction for stochastic ecological models with internal and external variables. Journal of Mathematical Biology, 79(1), 393-431 (2019). doi:10.1007/s00285019-01361-4

34. I. Chen, An evolutionary game study of an ecological industry chain based on multi-agent simulation: A case study of the poyang lake eco-economic zone. Sustainability 9(7).

(2017). doi:10.3390/su9071165

35. L. Dan, Research on innovation-synergy driven model for improving ecological competitiveness in resource-based city. Nature Environment and Pollution Technology 15(2), 515-520 (2016).

36. P. He-Si, L. Hong-Zhi, The evolutionary game analysis of cross-regional ecological compensation based on the perspective of the main functional area. E3S Web of Conferences 53 (2018). doi:10.1051/e3sconf/20185304043

37. R. Sigdel, M. Anand, C.T. Bauch, Convergence of socio-ecological dynamics in disparate ecological systems under strong coupling to human social systems. Theoretical Ecology 12(3), 285-296 (2019). doi:10.1007/s12080-018-0394-z

38. P. J. Vermeulen et al., An evolutionary game theoretical model shows the limitations of the additive partitioning method for interpreting biodiversity experiments. Journal of Ecology 105(2), 345-353 (2017). doi:10.1111/1365-2745.12706

39. MathCAD. Math software for engineering calculations, https://www.mathcad.com/en/. Accessed 29 Dec 2020

40. Welcome to Python, https://www.python.org/. Accessed 29 Dec 2020 